\title{
Isolation and Identification of Micro Organisms Present in Stethoscopes before and after Alcohol Swab Application
}

\author{
Celastina Synthia $\mathrm{X}^{1}$, Dr. Tasneem Banu, $\mathrm{MD}^{2 *}$ \\ ${ }^{1}$ MBBS II Year, Saveetha Medical College \& Hospitals, Thandalam, Chennai, Tamilnadu, India \\ ${ }^{2}$ Asstant Professor, Department of Microbiology, Saveetha Medical College, Kuthambakkam, Tamil Nadu 600124, India
}

\begin{abstract}
DOI: $10.36348 /$ SJPM.2019.v04i09.011 | Received: 13.09.2019| Accepted: 20.09.2019| Published: 30.09 .2019
*Corresponding author: Tasneem Banu
\end{abstract}

\section{Abstract}

\begin{abstract}
Aim: Nosocomial infections are of great concern in hospital settings especially in intensive care units. Health care professionals and their medical equipment have long been known to act as vectors of pathogens. This study aims at evaluating the presence of bacterial pathogens on stethoscopes of health care workers and to substantiate the effectiveness of alcohol swabs for decontamination of stethoscopes. Methods: 50 stethoscopes belonging to physicians, residents, interns and nurses were swabbed before and after decontamination with alcohol swab. The health care workers belonged to the medicine, surgery, obstetrics, paediatric wards and the intensive care unit. Results: $36 \%$ of the stethoscopes were contaminated. Decontamination with $70 \%$ isopropyl alcohol showed a significant decrease in contamination. The predominant organism isolated was Staphylococcus aureus (50\%). Conclusion: Nosocomial infections carry a higher level of morbidity and mortality. Most stethoscopes harbour potential pathogens. A change in the attitude of health care workers to disinfect their stethoscopes regularly and in between patients will bring about a break in the chain of transmission of infection. We recommend that disinfection of stethoscope should become an integral part of undergraduate and postgraduate education
\end{abstract}

Keywords: Nosocomial infection, stethoscopes, 70\% of isopropyl alcohol, disinfection.

Copyright @ 2019: This is an open-access article distributed under the terms of the Creative Commons Attribution license which permits unrestricted use, distribution, and reproduction in any medium for non-commercial use (NonCommercial, or CC-BY-NC) provided the original author and sources are credited.

\section{INTRODUCTION}

Physical examination is a necessary part of the diagnosis and treatment of patients in medical practice. Stethoscopes are invariably one of the most frequently used medical devices which come in contact with patients and patient surroundings [1]. They act as vectors of transmission for infection. The hospital environment is teaming with nosocomial flora in spite of routine disinfection. Nosocomial flora includes multidrug resistant pathogens like Methicillin Resistant Staphylococcus Aureus (MRSA), Vancomycin resistant Enterococci (VRE) and multi drug resistant enterobacteriacae and Pseudomonas. The fact that these potentially pathogenic organisms can survive on inanimate surfaces plays a pivotal role in the transmission of nosocomial infections [2]. Nosocomial infections, also known as hospital acquired infections (HAI) are contracted in a hospital environment after 48 hours of admission. The transmission mainly occurs through health care workers, devices and equipments. Presently there is an increasing trend of multi-drug resistant (MDR) pathogens causing nosocomial infections. Antibiotic resistance is directly proportional to the amount of antibiotics used. The most important preventive measure for transmission of nosocomial infections is handwashing. Simple measures such as disinfection of stethoscopes can also help in decreasing the spread of infections.

\section{AIM OF THE STUDY}

- To determine the presence of microorganisms on stethoscopes used by health care providers.

- To check the effectiveness of $70 \%$ of isopropyl alcohol in killing the microorganisms found on the stethoscopes.

\section{MATERIALS AND METHODS}

It is a hospital based study carried out in the month of January 2019 in a tertiary care institution SAVEETHA MEDICAL COLLEGE AND HOSPITALS, Chennai, Tamil nadu.

Here 50 swabs from the diaphragm of stethoscopes were collected from doctors, nurses and other healthcare workers before and after rubbing with $70 \%$ isopropyl alcohol. Swabs taken from the diaphragm - A swab before rubbing with $70 \%$ of 
isopropyl alcohol was labelled as "S" and after rubbing with $70 \%$ of isopropyl alcohol labelled as "AS". All the collected samples where inoculated within one hour into $5 \%$ of sheep blood agar and incubated at 33degrees for 24 hours.

The identification of bacteria was performed by conventional methods. For gram positive cocci tube and slide coagulation tests were done and for gram negative bacteria basic biochemical tests were done to confirm the identification.

\section{RESULTS}

Total swabs collected $=100$

$>50$ swabs before rubbing with $70 \%$ of alcohol swab (S).

$>50$ swabs after rubbing with $70 \%$ of alcohol swab (AS).

19 out of 50 swabs (38\%) before rubbing with alcohol grew micro organisms (Fig-1)

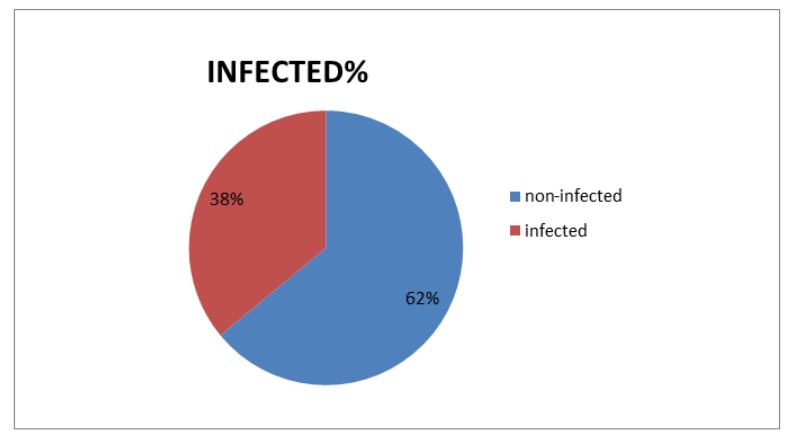

Fig-1: Percentage of Infected Stethoscopes
Five of the fifty swabs after decontamination with $70 \%$ of isopropyl alcohol still grew micro organisms (Fig-2).

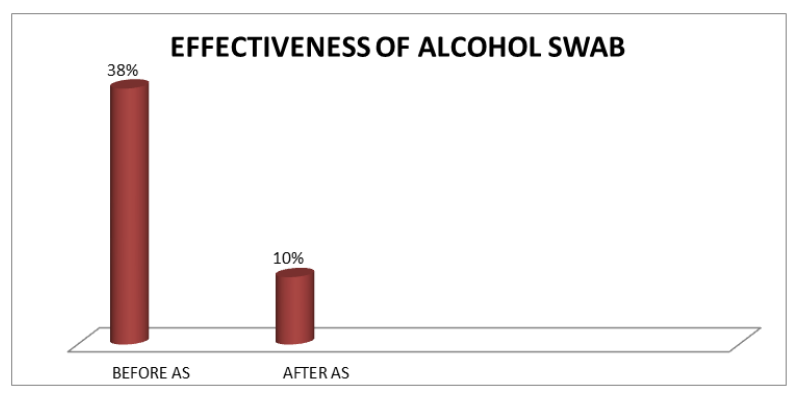

Fig-2: Effectiveness of Alcohol Swab

There is a drastic reduction (73\%) in microbial growth after cleaning with alcohol swab.

The number of swabs collected from the stethoscopes of health personnel working in different wards are depicted in Table-1.

Table-1: Number Of Swabs Were Collected From Different Wards

\begin{tabular}{|l|l|l|}
\hline $\begin{array}{l}\text { SL. } \\
\text { NO }\end{array}$ & WARD & $\begin{array}{l}\text { NO.OF } \\
\text { SWABS }\end{array}$ \\
\hline $1-10$ & General Medicine & 10 \\
\hline $10-20$ & Intensive Care Unit & 10 \\
\hline $20-30$ & $\begin{array}{l}\text { Obstetrics \& } \\
\text { Gynaecology }\end{array}$ & 10 \\
\hline $30-40$ & Surgery & 10 \\
\hline $40-50$ & Pediatrics & 10 \\
\hline
\end{tabular}

The different types of micro organisms found on the stethoscopes from various ward are shown in the Table-2.

Table-2: Organisms Grown From Swabs from Different Wards Prior To Decontamination

\begin{tabular}{|l|l|l|}
\hline SL.NO & WARD & ORGANISM \\
\hline 1 & General medicine & Staphylococcus aureus(2) Micrococci(2) \\
\hline 2 & Obstetrics \& Gynaecology & $\begin{array}{l}\text { Staphylococcus aureus(4) } \\
\text { Micrococci(1) } \\
\text { Klebsiella(1) }\end{array}$ \\
\hline 3 & & Micrococci(3) \\
\hline 4 & Surgery & Staphylococcus aureus(4) \\
\hline 5 & Pediatrics & Staphylococcus aureus $(\mathbf{2})$ \\
\hline
\end{tabular}

5 swabs out of fifty were still positive for microorganisms even after application of alcohol swab and the data is given in the Table-3.

Table-3: Organisms Grown From Swabs from Different Wards after Decontamination

\begin{tabular}{|l|l|l|}
\hline SL. NO & WARD & ORGANISM \\
\hline 1 & General Medicine & staphylococcus aureus(1) \\
\hline 2 & Obstetrics \& Gynaecology & staphylococcus aureus(2) \\
\hline 3 & Surgery & staphylococcus aureus(2) \\
\hline
\end{tabular}


The overall positivity rate of swabs and their percentages from different wards are shown below in Figure-3.

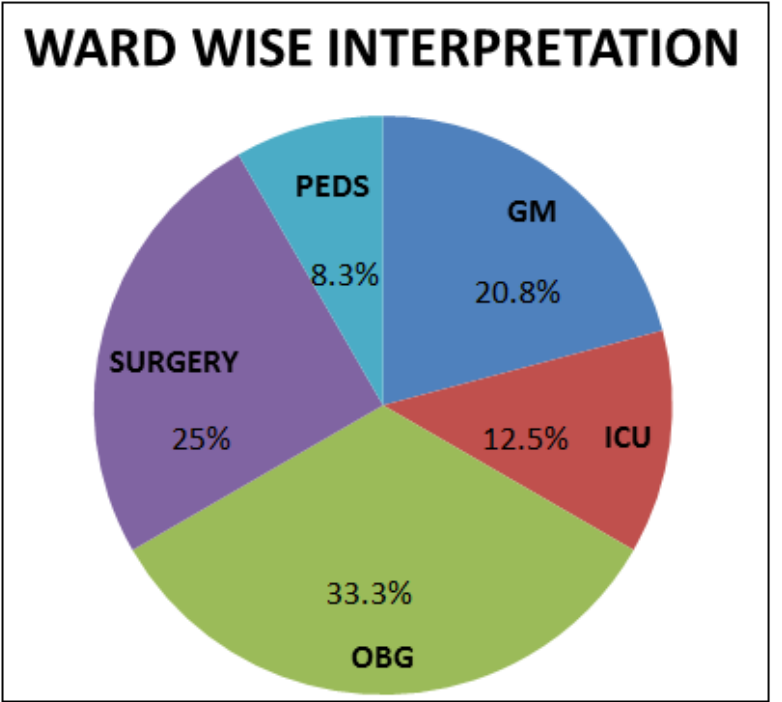

Fig-3: Contaminated Swabs from Different Wards

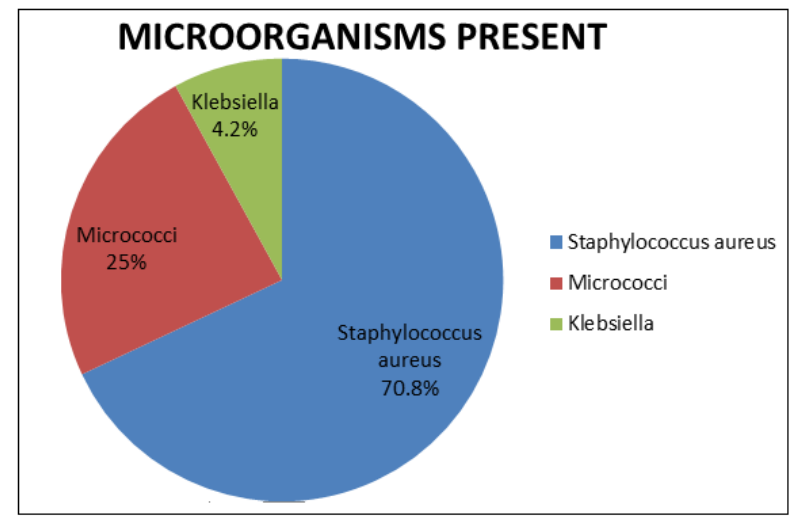

Fig-4: Percentage of Microorganisms Present In the Infected Stethoscopes

\section{DISCUSSION}

In our study, we found that $19(38 \%)$ of the stethoscopes used by the health care professionals were contaminated with microorganisms. The study by Youngster et al revealed $87.5 \%$ of contaminated stethoscopes [3]. Similar higher rates of contamination have been reported by Lokkur et al., [4]. However a lower rate of contamination is reported by others which is in accordance with our study. A study by Bukharie et al., only $30 \%$ of the stethoscopes were contaminated with micro organisms [5]. In study by Alothman A et al., total of $47.7 \%$ stethoscopes were contaminated, among which, $68.3 \%$ were from physicians [6]. In the study by Kuhu $\mathrm{Pal}$ et al., 52\% of the stethoscopes were contaminated [8]. Only one study Bukharie et al., had contamination rates less than us.

There was a $28 \%$ decrease in the contamination rate of our stethoscopes compared to the global average.
10 stethoscopes were analyzed each from Intensive care unit, General medicine, Surgery, Paediatrics and Obstetrics and Gynaecology wards. 19 out of $50(38 \%)$ stethoscopes were positive for microbial contamination. Even after decontamination with alcohol swabs, 5 (26.3\%) stethoscopes still had microorganisms. The efficacy of isopropyl alcohol was calculated to be $73.7 \%$. Nunez et al., have found out that there were bacterial contamination to an extent of 132 colony forming units per stethoscope in their study. Disinfecting the stethoscope diaphragm with iso propyl alcohol resulted in an immediate reduction in the bacterial count to 0.3 colony forming units per stethoscope and concluded that propyl alcohol-based disinfectants had the best results $99 \%$ reduction of colonies [9]. In study by Lokkur et al., there was decrease in colony forming units from 15.38 to 1.54 when alcohol was used for decontamination [4]. $70 \%$ isopropyl alcohol rub showed a significant reduction of contaminating organisms from $38 \%$ to $10 \%$ in our study. Schroederet al have found that cleaning the stethoscope heads reduces bacterial counts on stethoscopes [7].

When we consider the distribution of contaminated stethoscopes, $33.3 \%$ was found to be from Obstetrics and Gynaecology department which is in accordance with the study by Kuhu et al., (34.6\%) [8].

The predominant microorganism isolated in our study was Staphylococcus aureus which constituted $70.8 \%$ of the total microorganisms followed by Micrococci (25\%) and Klebsiella (4.2\%). Alothman et al have reported the presence of coagulase negative staphylococcus (92\%) and micrococci $(8 \%)$ from 13 swabs (18\%) [6]. In the study by Youngster et al., Staphylococcus was the predominant organism (47.5\%). Huda et al., had $29.7 \%$ of gram positive cocci and gram negative bacilli [3]. Nunenz et al., had $40 \%$ of micrococci which was similar to our study [9]. Longtin et al., had $20 \%$ enterococcus and $7 \%$ enterobacteriace [10]. Alothman et al., had $92 \%$ of Coagulase negative Staphylococcus.

\section{CONCLUSION}

The overall contamination rate of stethoscopes is very less compared to the global average. That coupled with a minimal percentage of enterobacteriace isolated, gives us a strong platform to work ahead against spread of nosocomial pathogens.

\section{REFERENCES}

1. Jain, A., Shah, H., Jain, A., \& Sharma, M. (2013). Disinfection of stethoscopes: gap between knowledge and practice in an Indian tertiary care hospital. Annals of Tropical Medicine and Public Health, 6(2), 236-239.

2. Kramer, A., Schwebke, I., \& Kampf, G. (2006). How long do nosocomial pathogens persist on 
inanimate surfaces? A systematic review. BMC infectious diseases, 6(1), 130.

3. Youngster, I., Berkovitch, M., Heyman, E., Lazarovitch, Z., \& Goldman, M. (2008). The stethoscope as a vector of infectious diseases in the paediatric division. Acta Paediatrica, 97(9), 1253-1255.

4. Lokkur, P. P., \& Nagaraj, S. (2014). The prevalence of bacterial contamination of stethoscope diaphragms: A cross sectional study, among health care workers of a tertiary care hospital. Indian journal of medical microbiology, 32(2), 201-202.

5. Bukharie, H. A., Al-Zahrani, H., Rubaish, A. M., \& Abdulmohsen, M. F. (2004). Bacterial contamination of stethoscopes. Journal of family \& community medicine, 11(1), 31-33.

6. Alothman, A., Bukhari, A., Aljohani, S., \& Muhanaa, A. (2009). Should we recommend stethoscope disinfection before daily usage as an infection control rule?. The Open Infectious Diseases Journal, 3(1), 80-82.
7. Schroeder, A., Schroeder, M. A., \& D'Amico, F. (2009). What's growing on your stethoscope?(And what you can do about it) Alcohol-based foam can do double duty, cleansing hands and stethoscope heads with a single scrub. Journal of Family Practice, 58(8), 404-410.

8. Pal, K., Chatterjee, R., Biswas, A., \& Samanta, A. K. (2015). Bacterial contamination and disinfection of stethoscopes: a knowledge gap among health care personnel of a tertiary care hospital of rural Bengal. IOSR-JDMS, 14(7), 4449.

9. Nunez, S., Moreno, A., Green, K., \& Villar, J. (2000). The stethoscope in the emergency department: a vector of infection?. Epidemiology \& Infection, 124(2), 233-237.

10. Longtin, Y., Schneider, A., Tschopp, C., Renzi, G., Gayet-Ageron, A., Schrenzel, J., \& Pittet, D. (2014, March). Contamination of stethoscopes and physicians' hands after a physical examination. In Mayo Clinic Proceedings, 89(3):291-299. 